\title{
Acid-fast bacilli culture positivity and drug resistance in abdominal tuberculosis
}

\author{
Sora Yasri • Viroj Wiwanitkit
}

Published online: 3 October 2014

(C) Indian Society of Gastroenterology 2014

Sir:

The recent report on acid-fast bacilli culture positivity and drug resistance in abdominal tuberculosis is very interesting [1]. Samant et al. found that acid-fast bacilli (AFB) culture positivity was averagely $50 \%$ and the resistance was detected in estimated $15 \%$ [1]. In fact, the detection rate of AFB organism in non-sputum specimen is usually low. Although the technique used in this report, BACTEC, is acceptable, there are also some laboratory concerns. The contamination is the important consideration to be aware of in using BACTEC [2]. In addition, the false-positive result for drug resistance is also observed in using BACTEC [3]. Piersimoni et al. suggested using "reduced inoculum (RI) assay to confirm all PZA resistance results obtained" [3]. To increase the detection rate, the use of molecular diagnosis tool can be helpful [4]. However, in resource-limited setting, the alternative use of "BACTEC combined with conventional solid medium" can also be a good alternative to increase the chance for yield of organism [5]. Based on the rather high drug resistance rate in the present report, it is necessary to find a more diagnostic tool for determination of the organism.

\section{References}

1. Samant H, Desai D, Abraham P, et al. Acid-fast bacilli culture positivity and drug resistance in abdominal tuberculosis in Mumbai, India. Indian J Gastroenterol. 2014;33: 414-9.

2. Hanna BA, Ebrahimzadeh A, Elliott LB, et al. Multicenter evaluation of the BACTEC MGIT 960 system for recovery of mycobacteria. J Clin Microbiol. 1999;37:748-52.

3. Piersimoni C, Mustazzolu A, Giannoni F, Bornigia S, Gherardi G, Fattorini L. Prevention of false resistance results obtained in testing the susceptibility of Mycobacterium tuberculosis to pyrazinamide with the Bactec MGIT 960 system using a reduced inoculum. J Clin Microbiol. 2013;51:291-4.

4. Kunduracioğlu A, Karasu I, Biçmen C, Ozsöz A, Erbaycu AE. Comparison of the performances of MTD Gene-Probe ${ }^{\circledR}$ test, BACTEC $960^{\mathrm{TM}}$ system and Löwenstein-Jensen culture methods in the diagnosis of smear-negative tuberculosis cases. Mikrobiyol Bul. 2013;47:417-31.

5. Chien HP, Yu MC, Wu MH, Lin TP, Luh KT. Comparison of the BACTEC MGIT 960 with Löwenstein-Jensen medium for recovery of mycobacteria from clinical specimens. Int J Tuberc Lung Dis. 2000;4: 866-70.
S. Yasri $(\bowtie)$

KMT Primary Health Care Center, Bangkok, Thailand

e-mail: sorayasri@outlook.co.th

V. Wiwanitkit

Hainan Medical University, Haikou, China 